\title{
The Jordanian Legal Protection of Disabled Persons in Accordance to International Human Rights Treaties
}

\author{
Sabah Al-Anizat ${ }^{1} \&$ Abdelsalam A. Hammash ${ }^{2}$ \\ ${ }^{1}$ Faculty of Education, World Islamic Sciences and Education University, Amman, Jordan \\ ${ }^{2}$ Faculty of Law, World Islamic Sciences and Education University, Amman, Jordan \\ Correspondence: Abdelsalam A. Hammash. E-mail: hammash23@gmailcom
}

Received: March 9, $2020 \quad$ Accepted: March 28, $2020 \quad$ Online Published: June 29, 2020

doi:10.5539/ass.v16n7p128 URL: https://doi.org/10.5539/ass.v16n7p128

\begin{abstract}
This study aims at analyzing the legal system for protection of individuals with disabilities in Jordan, especially after the ratification of the 2007 Convention on the Rights of Persons with Disabilities by Jordan. Then, the Jordanian Kingdom presented three-step measures to guarantee the rights of disabled persons. First, it introduced specific laws into the national legal corpus. Secondly, it made up a three-year strategy to enhance the protection of this particular panel of the population. Thirdly, a special committee was established whose duty is to assess the adequacy of national laws to the International treaties.
\end{abstract}

\section{Questions}

1) What is the significant contents of the 2007 UN Convention on the rights of Persons with disabilities?

2) What are the main characteristics of the Jordanian legal system dealing with those persons?

3) What are the lacks of the national legal system regarding to the 2007 International Convention?

\section{Methodology}

This research is based on the qualitative research methodology, where the adopted methods to be used in achieving the objectives of research are the following:

- Synthesis approach

- Analytical research method.

- Comparative study

- Empirical study

- The study has to go through the examination of a specific International treaty in a comparative study with the existing Jordanian legal system.

\section{Introduction}

The Hashemite Kingdom of Jordan has initiated a positive path to the consideration of the rights of persons with disabilities, according to international Conventions urging the care and protection of this specific range of the population. Jordan was among the first countries to comply with global developments in the field of disability, in the form of international agreements and treaties. Jordan signed the international agreement on the $3^{\text {rd }}$ of March 2007 and ratified it in 2008. As such, its commitment is to implement all the provisions of the agreement and to achieve its main goals. Mainly, to protect the rights of disabled persons and to ensure the full enjoyment of all human rights and fundamental freedoms. These commitments have been published in the Official Gazette to become a major part of national legislation. With Jordan's ratification of this agreement, it now has a set of obligations at the international and domestic levels. At the international level, and according to the provisions of Article 35 of the agreement, Jordan is obliged to submit to the Committee on the Rights of Persons with Disabilities a comprehensive report on its obligations and pledges to implement the provisions of the agreement after two years from ratifying the agreement and then submitting a report once every four years, and whenever the committee would request it. 


\section{The Jordanian Strategy for the Protection of Disabled Persons' Rights}

On the national level, by order of His Majesty King Abdullah II, a comprehensive local strategy was established with the active participation of persons with disabilities and all concerned parties, for the period from 2007 to 2015. The involvement of disabled persons in the process-making would make the strategy more adequate and purposefully designed. The Persons with Disabilities Law No .31 (2007) was issued and the Supreme Council for Persons with Disabilities was established following the provisions of Article 6 of the Persons with Disabilities Act as a national institution to support and defend their interests, formulate policies, plan and coordinate with all agencies concerned, and educate on the rights of people with disabilities. Moreover, removing physical barriers and obstacles to enable disabled people's effective participation in the society as well as providing a database based on the results of relevant studies and research are two main focuses of the legislative strategy.

\subsection{The Jordanian Law and the Guarantee of the Disabled Persons' Rights}

In June 2017, a new law was issued under No .20 (2017) and labeled as Special Rights of Persons with Disabilities. This specific law came up to enable persons with disabilities in Jordan to enjoy a legislative environment free of obstacles and barriers. It is based on the principle of equal opportunities and non-discrimination. It is very important because it is the first law tackling discrimination against persons with disabilities in the region. It imposes on all governmental and public institutions to include the issues inherent to disability in their strategies, plans, and programs. They must ensure facilitating access to persons with disabilities to all services and facilities. It includes amendments to penal law. Indeed, sanctions consider henceforth disability as an aggravating circumstance for crimes of abuse ,physical and psychological neglect against people in charge of their care as well as fraud, which came to complete the system of protection. In terms of protection from violence and to ensure the independence of persons with disabilities, the law has set a holistic definition. Depriving a person of the exercise of one of his rights or freedoms is a punishable crime, as well as the law prohibits any forms of violence, --physical and psychological,-which would affect persons with disabilities. The law has mentioned in previous legislative definitions and provisions for special approval free and informed consent. They included the consent of the person with a disability in a manner understandable to all that my shall take the right of the actions or acts of legal practices, including in that the consent of the person to deposit in the role of care and AlAnkh Framework in the different programs of rehabilitation. In the field of education, the law has newly enjoined to the Ministry of Education to provide 'facilitative and reasonable arrangements in schools, governmental and private , and to prevent the exclusion of any person from any educational institution based on disability'. Therefore, the ministry committed to accept the integration of children with disabilities in educational institutions, and promote a culture of difference through including curricula and school concepts to promote the rights of persons with disabilities. It also dealt with the health sector. Indeed, in a number of articles, the law has enjoined the Ministry of Health to provide reasonable facilities and easy access to hospitals and public medical centers, besides, to correct the situation of institutions and health within 5 years to design and implement programs to detect earlier disability in hospitals and health centers to reduce the aggravation of disability.

Under this law, to secure the health of persons with disabilities will receive treatment ,medicines and surgeries, vaccines and natural treatment, sessions of speech aids, assistance, including headphones, glasses, and lenses. The law also includes aspects representative of the priorities of the persons with disabilities ,such as access to employment ,courts, and the services of defense ,roads ,sidewalks ,media ,culture ,tourism ,sports ,banking.

\section{The Fundamental Liability of the United Nations Convention on the Rights of Persons with Disabilities}

The Resolution 56/168 of the December 19, 2001 of the UN General Assembly appealed to form a committee to consider proposals for the preparation of an integrated comprehensive convention to promote and protect the rights of persons with disabilities and to guarantee their dignity. Its first meeting took place in July 2002. In June 2003, the Committee decided at its second meeting to set up a working group aiming to prepare and submit the text of the Convention draft. The Working Group met for a two-week session in January 2004 and completed the preparation of the full text of the Convention draft. During the first session of the General Assembly, the Secretary-General requested in its Resolution 57/229 the 18th December 2002 'to seek the relevant organizations of the United Nations system on the proposals relating to the Convention'.

\subsection{The Role of Specialized Organizations}

The presence of non-governmental organizations efficiently working in the field of disability in meetings and mediations was a very good sign in the protection of disabled persons. The first time that non-governmental organizations and human rights institutions were allowed was during the preparation of the drafting of the texts 
of agreement from 40 members including 27 governments and 12 NGOs and a human rights institution. Arab countries in this group were represented by Lebanon and Morocco at the level of countries and Jordan at the level of NGOs. In the Resolution 58/246, the United Nations General-Assembly asked the ad hoc committee to start negotiations for a draft Convention. This committee met twice annually, and on the 25th August 2006, the committee adopted without a vote the draft text of the Convention on the Rights of Persons with Disabilities. On the 13th of December 2006 the agreement was adopted by Resolution No. 61/106 and opened for signature on 30 March 2007. The agreement was implemented on July 1, 2008, after 19 member States ratified it, while its optional Protocol 18 was ratified.The two instruments entered into force on the third of May and 2008 ,after the agreement obtained the first twenty ratifications, and after the protocol obtained the first ten ratifications.This agreement was the response of the international community to the long history of discrimination against persons with disabilities and their exclusion and dehumanization. The three-year negotiations on it were the fastest ever to take place on a human rights convention in history, the first human rights convention to be held in the twenty-first century.

At its eighth session, on 5 December 2006, the Committee referred the draft final report, together with the text of the Convention and the Optional Protocol, to the General Assembly for adoption .On the 13th of December 2006, the General Assembly adopted the Convention and its Optional Protocol by its Resolution 61/106. The General Assembly urged member states to consider signing and ratifying them as a matter of priority .The General Assembly also requested the Secretary-General to submit at its sixty-second session a report on the status of the Convention and the Optional Protocol and to work on the progressive application of the standards and guidelines that allow access to the services of the United Nations system .It also requested the specialized United Nations agencies to make efforts to publish information related to the Convention and the Optional Protocol. It is the first comprehensive human rights convention in the $21^{\text {st }}$ century to be opened for signature by regional integration organizations, and it constitutes a shift in attitude and approach towards persons with disabilities .This agreement reflected the transformation helps to enable persons with disabilities to exercise their rights , and to ensure their effective participation in cultural, social, economic, and political life.

\subsection{The First Requirement of the United Nations Convention on the Rights of Persons with Disabilities}

The 2006 Convention on the Rights of Persons with Disabilities is unique, and differs in terms of details from other human rights instruments, although it maintains the general form of human rights covenants in terms of emphasizing reference, sources, and basic principles of human rights. However, it differs in terms of content from other covenants, because it concerned people with disabilities.

The agreement adopts the most advanced visions of people with disabilities, and it emphasizes on the barriers that disabled face daily, starting from the widespread ignorance of their affairs to their potential .The agreement also adopted the social theory of disability, which sees disability in 'environmental barriers and not in physical or sensory impairment'. The agreement opened the doors towards hope for a social group that has suffered for centuries and continues to suffer in various degrees for the most marginalized examples. Besides, it helped to achieve a better understanding of disability and called for change the reality of the rights of persons with disabilities in all categories and their protection. In other terms, it represented a message of concern that the disability is not a negative concept; most disabled persons can convert their energies into productive capacity in the family, school, and community. This message can be introduced by investing in communication tools, ideas, experiences, and skills that can be provided.

A question that may arise is the reason for adopting this agreement, while there is already a corpus of international covenants that discussed human rights and their application regardless of any criterion of discrimination, such as the 1948 Universal Declaration of Human Rights, the International Covenants on Human Rights, mainly. The reason for concluding this agreement is to meet the reasons for the development taking place in dealing with the disability and the life of the disabled, as many violations of the rights of persons with disabilities have been uncovered .Consequently, the need to criminalize actions that were not considered as criminal beforehand has emerged, similar to the claim to provide disabled with rights specific to their condition Scientific progress was also reflected positively on disability issues in all its aspects, especially in prevention, treatment, rehabilitation, and integration.

\subsection{1}

This agreement is a supplement to human rights conventions, and it does not recognize any new human rights for persons with disabilities, but rather clarifies States' legal obligations to respect all persons with disabilities and ensure a guarantee of all their human rights .It also sets global standards that should be applied to everyone. Countries are obliged to consult with persons with disabilities by organizations representing them, when they 
develop and implement legislation and policies to implement the Convention and on all other public policy issues affecting their lives.

\section{2 .2}

The agreement indicated that its main achievement is to promote, protect, and ensure that all persons with disabilities full and equal enjoyment with others of all human rights and fundamental freedoms.

\section{2 .3}

The Convention affirmed equality and non-discrimination ,by requesting the States parties to recognize that all persons are equal before the law, and they have the right without any discrimination and on an equal basis to protect it equally and effectively. States parties to the Convention banned unconditionally any discrimination based on disability .The scope of this agreement is limited to promoting and protecting the rights of persons with disabilities in economic, social, political, legal and cultural life, non-discrimination in treatment, equal access to justice in the treatment of courts and the police for them, and in carrying out administrative tasks by providing the necessary reasonable, procedural and appropriate amenities for their ages in education, health, work, family protection, and participation in political and public life. Despite the provisions of the accuracy of this Convention and its emphasis on full equality, it has been overlooked that the people with disabilities need positive discrimination in this regard because equated with non-disabled people lose their ability to compete with them in various fields. The convention required State parties to take the necessary measures to ensure that persons with disabilities effectively enjoy the right to life on an equal basis with others.

The indicated agreement to situations of risk and humanitarian emergencies faced by the disabled ,so States Parties comply with their obligations under international law, including international humanitarian law and the international human rights law, to take all necessary measures to ensure the protection and safety of persons with disabilities who are in situations of risk. This includes situations as armed conflicts, humanitarian emergencies, and natural disasters. The agreement dealt with the recognition of persons with disabilities as persons with legal responsibility and enjoying legal liability on an equal basis with normal persons in all aspects of life. States parties have to ensure the implementation of appropriate and effective measures related to the exercise of legal guarantees to prevent misuse of these measures under international human rights law. The agreement ensures the rights of persons with disabilities to live independently and in a full integration into society, to choose their place of residence and the people who live with them, to ensure their right to education, and the enjoyment of the highest standard of health, as well as in ensuring their right to work, and the ability to participate effectively in political life. The drafters of the agreement emphasized on rehabilitation, as they requested the States parties to provide comprehensive services and programs for rehabilitation, promotion, and expansion of their scope in the fields of health, work, education, and social services.There is no doubt that the Convention on the Rights of Persons with Disabilities represents a shift in the way societies deal with persons with disabilities, where the person is the main decision-maker in his life by enjoying all the rights and duties imposed by the law with full participation in formulating and implementing plans and policies that affect them.

The drafters asked the State parties to identify and eliminate obstacles and barriers that hinder the ability of persons with disabilities to access the environment around them and to enjoy their inherent right to life on an equal basis with others: the right to education, health care, rehabilitation, to work and employment, the right to an adequate standard of living and social protection. The Convention recognized that certain persons are subject to discrimination not only based on disability but also on other grounds, as women with disabilities, and children with disabilities. Therefore, the Convention has arranged obligations on State parties by taking all legislative and administrative measures to implement the rights recognized in the agreement, as follows:

-raise awareness so that people with disabilities understand their rights and duties.

-access to enjoy all rights.

-situations of risk and humanitarian emergencies warrant ensuring protection for persons with disabilities.

-the possibility of resorting to the judiciary to claim their rights.

-personal mobility to enhance their independence.

-rehabilitation in order to achieve the maximum independence and capacity.

-collecting statistics and data for persons with disabilities such as the workforce, education, women, the elderly, to encourage governments to use these statistics as a basis for formulating and implementing policies to promote and protect the rights of persons with disabilities, as well as to include their issues in their programs. These statistics must report all groups, such as deafness, dumbness, blindness, and others, in order to determine their 
qualifications and the aids that can be offered to them. While identifying and recognizing each different category of persons with disabilities, the agreement emphasized on the unity and indivisibility of rights .Despite all these positive steps towards the recognition of disabled persons'rignts and their need for the implementation of specific legislation remain the issue of granting persons with disabilities excellence that is to say, the positive necessary important and issue to facilitate the process of their enjoyment of their fundamental rights in a practical and realistic framework.

The 2006 Persons with Disabilities Agreement is one of the first and most important international instruments that included development and social dimensions, in addition to its legal and political dimensions .It is a valid international agreement to be a tool for comprehensive community development, especially as it defined the rights of persons with disabilities and indicated how they enjoy individual rights and provided practical procedural measures that states parties can adopt in support of development programs that promote and guarantee the rights of persons with disabilities and activate their societal participation.

This agreement remains very important for persons with disabilities, especially as it views them as people with rights and not merely as persons in need of social or health care .It also recognizes that although they have the theoretical right to all human rights, they are still virtually deprived of these rights.

\section{General Legal Obligations of the State's Parties to the Agreement}

Article (4) of the Convention on the Rights of Persons with Disabilities urges states parties to 'ensure and promote the full realization of all human rights and fundamental freedoms for all persons with disabilities without any discrimination of any kind on the basis of disability'. Therefore, States are required to 'refrain from any action or 'practice inconsistent with the agreement', and also to 'take all appropriate legislative, administrative and other measures to enforce the rights recognized in this agreement'. Human rights treaties have shown that appropriate measures to implement obligations have multiple facets, such as administrative, legislative, judicial, educational, social, and financial measures. Although the agreement requires the States parties to commit to taking the necessary measures, it adopts a flexible approach in terms of implementation that takes into account the legal discretion of each country, such as the status of the treaty in the domestic legal system in each country, with a focus on the need to choose the appropriate means to implement these obligations. ,Paragraph (3) of Article (4) also obliges States parties to comprehensively consult and involve persons with disabilities in order to develop and appropriate legislation and policies to implement the provisions of the agreement concerning civil, cultural, social, political and economic rights. To this end, the agreement imposed two types of obligations on the States parties, namely general obligations that urge States parties to take the necessary measures to implement the agreement, and detailed obligations that show how the terms of the agreement should be implemented.

\subsection{General Obligations of the UN Treaty}

States parties have to promote and guarantee the achievement of human rights and freedoms for all, and more specifically for persons with disabilities without any discrimination of any kind on the basis of disability.

The agreement aims to integrate people with disabilities in various areas of life and remove all forms of barriers: (social, material, and legal) that prevent them from obtaining and enjoying their rights. This approach aims at defining people with disabilities from a social perspective that is to say any individual who suffers from a permanent physical, mental, or intellectual disability, taking into account that this disability may prevent them from participating fully and effectively in society, along with others .To this end, the States Parties accept to adopt any appropriate measures as required by the Agreement. For example, Article 12 of the Convention urges States parties to recognize the right of persons with disabilities as persons liable before the law , and the recognition of their eligibility on the ground of equality with others. According to paragraphs 3 and 4 of Article (12), any appropriate measures to provide persons with disabilities with eligibility. It also ensured that the States Parties shall prevent the misuse of these measures under international human rights law. The implementation of the obligations in the paragraphs of Article 12 contained a comprehensive and accurate review of both civil and criminal legislation. It includes civil elements based on equality: ownership, property inheritance, affairs, management, finance, and the granting loans of bank mortgages or any other forms of financial, credit and to ensure not to deny them of their property arbitrarily.

The second facet of the measures advocates that States, shall amend or cancel any laws or customs that may constitute discrimination against persons with disabilities. To conclude, the legislation must include guarantees of public equality and non - discrimination in both governmental and private activities of the state. These guarantees include all forms of discrimination based on disability, as well as the expansion of guarantees to include the provision of guarantees of equality to all individuals related to persons with disabilities such as 
parents and brothers.

Likewise, legislation should provide clear and facilitative arrangements of a compulsory nature for public and private bodies to ensure equal access for persons with disabilities to the services or activities of these bodies . Equality legislation must provide for positive or temporary positive measures to promote de facto equality for persons with disabilities. States have the discretionary power to choose the most appropriate approach to their specific legal systems. Either the state enacts a comprehensive law relating to people with disabilities, equality, and non-discrimination that includes various sectors in the state, or that disability is included in general legislation and then guarantees related to equality and non-discrimination are included in sectoral legislation, as well as taking judicial measures and the necessity to address cases of violations of these rights, whether these rights are social, cultural, civil, political or economic, which requires the state parties to provide appropriate training to the judiciary according to the agreement pursuant to Article 13.The Agreement advocates that all policies and programs should adopt comprehensive standards and guideleines to protect and promote human rights. The goal is to break the barriers that this specific group of the population may encounter in his daily life to be able to access the services and facilities available to general public.

States shall take the adequate and necessary measures to comply with the Agreement As such, the text insists on the fact that States shall 'refrain from any action or practice that is inconsistent with this agreement and ensure that public authorities and institutions act in a manner consistent with it. This part of the agreement deals most with the protection and the guarantee of freedom and security in healthcare. More precisely, it targets to the forced deposit of people with disabilities to specialized institutions without their consent. Indeed, paragraph (1 / b) of Article (14) states that 'the existence of a disability shall not be justified in any way for any deprivation of liberty' This approach prevents deprivation of liberty based on the existence of any disability. Thus, it requires the abolition of legislation and provisions that allow the placement of persons with disabilities in internal institutions for their care and treatment without taking their consent in addition to the provisions that allow for preventive detention of persons with disabilities in cases where the disabled person poses a potential danger to himself or others as a result of an apparent or diagnosed mental illness, bearing in mind that this does not mean that they are not legally detained or that they are held in pretrial detention to receive care and treatment ,but rather that the legal reasons for restricting freedom are handicapped and impartially and that they apply to all persons and equality. As we noted previously, one of the major principles is to prevent any discrimination based on disability from a person, or an organization, or a private institution. That is why this non-discriminative principle is enshrined in many parts of the agreement. In the preamble it appears in paragraphs $(\mathrm{a}, \mathrm{b}, \mathrm{c}, \mathrm{d}, \mathrm{e}, \mathrm{f}, \mathrm{t}$, y), and in it appears also in Article No. (1), in the general principles, it appears in Article No. (3), and in the general obligations of states, it appears in Article No. (4.

Article (5) recognizes that 'all are equal persons before the law and are entitled without discrimination and equal protection and benefit of the law', and paragraph (2) of Article (5) the obligation of States parties 'to prohibit any discrimination on the basis of disability', known as Article (2) From the agreement, discrimination on the basis of disability is that: 'Any discrimination, exclusion or restriction on the basis of disability whose purpose and effect is to weaken or frustrate recognition of all human rights and fundamental freedoms or to enjoy or exercise them on an equal basis with others in the political, economic or social, cultural, civil or any other field', 'deprivation of reasonable accommodation arrangements means" reasonable accommodations' as mentioned in Article (2) of the agreement as: 'necessary and appropriate amendments and arrangements that do not impose a disproportionate or unnecessary burden and that are needed in a specific case to ensure the enjoyment of persons with disability, on the basis of equality with others, with all human rights and fundamental freedoms and their exercise. ' The broad conditions mentioned in Article 5 must be linked to specific measures of non-discrimination and equality associated with a wide range of civil rights contained in the agreement, such as: marriage, family, parenthood and marriage in Article (23), education (Article 24), health (Article 25), employment (Article 37), a decent standard of living and social protection in Article (28), and participation in political and public life (Article 29). Moreover, Article (2) states that: 'Carrying out or enhancing research and development of goods, services, equipment and utilities that are generally designed, which must require a minimum level of adaptation and costs to meet the specific needs of people with disabilities, as well as encouraging their provision and use, and promoting general design when setting standards and guidelines, as well as providing technological means such as information and communication technology, mobility aids and devices and assistive technology, while giving priority to available technology at reasonable prices and easy access to it'.

Besides, so that the rights of disabled persons be guaranteed, the agreement recommends the training of specialists and staff working with persons with disabilities to improve the provision of assistance and services. Finally, States have to take on the necessary judicial measures so that they may have a legally binding meaning 
and that the judiciary could be an effective and equitable body to address whenever any violation may occur.

Concerning economic, social, and cultural rights ,all State parties have to take on the necessary measures within the framework of international cooperation, to gradually achieve the full attainment of these rights, without prejudice to the obligations contained in this agreement and applicable immediately according to International law. For example, Article 24 of the Convention requires the right of persons with disabilities to education within the framework of an inclusive education system and the removal of legal barriers to the integration of persons with disabilities in the conventional education system of the country. It requires removing direct and indirect barriers in each of the acceptance and the education stages to identify needs and to provide reasonable adjustment to the requirements of the national legislation. These obligations are clearly defined for all since education in the public or the private sector remains under the prerogatives of the Ministry of Education The Ministry is the only institution responsible for the education of people with disabilities and that laws that include education for people with disabilities are repealed in the jurisdiction of the social welfare sector. Therefore, it applies to obligations related to the right of persons with disabilities to compulsory and free primary education. Thereby, states may formally define the standards of education that ensure that 'persons with disabilities can benefit on an equal basis with others by obtaining an accessible, acceptable, adaptable and accessible education and providing adaptable school curricula to develop and enhance a sense of dignity and human value and develop the personality of persons with disabilities and develop their talents, creativity and participation with them'.

As for the right of persons with disabilities to work, Article (27) of the Convention affirms this right on an equal basis with persons without disabilities. As the agreement prohibits any discrimination on the basis of disability and obliges the State parties to provide reasonable adjustments in terms of employment, appointment, work, career advancement, and work conditions. It even goes beyond since it guarantees also equal pay for equal work, their right to exercise trade union rights. More generally, the agreement recommends taking all positive measures to ensure an open labor market that receives people with disabilities and promoting free employment opportunities for them. It underpins the existence of national legislation related to the work of persons with disabilities and a set of special legal provisions to encourage their entry in the labor market. For example, the appointment of disabled persons is subjected to a quota to guarantee them the opportunity to work. Likewise, financial aids may be paid to employers in the form of tax cuts to encourage them to employ disabled persons. Finally, guidance and professional employment services must be offered accordingly.

\subsection{Consultation and Data Collecting}

The Agreement reinforces the necessity of active consultation and participation of disabled persons, including children, in the representative organizations. Their participation help to ensure the development and implementation of legislation and policies abiding with the provisions of the Convention.

The agreement mentioned also the process of collecting statistics and data on people with disabilities to be used in the preparation and implementation of the provisions. However, this process must comply with the legal protection to ensure confidentiality and respect of privacy, as well as ethical principles in the collection and use os statistics. The main purpose of the collection of data on disabled persons is to assess the obstacles that they face in their daily life so that the provisions implemented by each State be the most accurate and appropriate response to their problems. States parties must publish these statistics and ensure that they are available to all persons with disabilities and others.

\subsection{International Cooperation}

International cooperation includes different forms: cooperation with relevant international, cooperation with regional organizations, cooperation with civil society organizations, especially organizations of persons with disabilities. The necessary measures to achieve this cooperation must be comprehensive and beneficial for disabled persons mainly through the exchange and sharing of information and experiences and training programs. Most emphasis is put on cooperation in the field of research and scientific and technical knowledge. Furthermore, technical and economic assistance will appropriately facilitate the access and the sharing of technology.

\section{Legal Measures for Monitoring at the National Level}

The Convention on the Rights of Persons with Disabilities referred to two types of mechanisms for monitoring the implementation of States parties' obligations: national monitoring mechanisms and international monitoring mechanisms. Consequently, this agreement is the first human rights treaty that contains detailed provisions on the establishment and functioning of national monitoring and implementation frameworks, including them as measures to provide the necessary institutional preconditions to ensure the realization of the rights contained in 
the agreement. Article (33) of the agreement relating to implementation and monitoring at the national level obliges States parties to establish mechanisms to implement the agreement and monitor it at the national level . On the national level, the agreement requires the presence of at least one central government point for this responsibility, and the parties vary in the number of government representatives and observers to implement the agreement. The agreement also encourages that there would be a mechanism within the government to coordinate actions taken at various levels and sectors, and for every country. Independent bodies such as the Human Rights Commission or the Disabled Rights Commission could be responsible for following up national laws and to monitor how the agreement is put into practice. The agreement also includes that NGOs and especially organizations of persons with disabilities have the right to participate fully in the national monitoring process. This participation is one of the requirements of the treaty, and States parties are required to submit reports to the International Committee of Experts that include persons with disabilities and other persons elected from countries that have ratified the treaty. These reports show the country's progress to abide by the provisions. The agreement requires each country to submit an initial comprehensive report with attached reports every four years, for which observations and recommendations will be communicated by the committee subsequently.

The mechanisms to monitor the extent to which States parties implement their obligations under the agreement are divided in two categories. The first are coordination mechanisms available at the government level, and the second are national monitoring mechanisms for the implementation of the obligations of states.

\subsection{Coordination Mechanisms Available at the Governmental Level}

Coordination is realized through the establishment of one or more governmental bodies whose purpose is implementing the agreement. However, the agreement did not specify the name of this agency or the number of its members and their qualifications, as this responsibility was left to the states parties to organize it and determine the governmental agencies affiliated with it. At the same time, it did not leave this issue without control. Indeed, the States Parties shall take into consideration in designing or establishing this mechanism that the principles relating to the status and methods of work of national institutions shall always comply with the protection and promotion of human rights. Accordingly, non-binding UN organizations such as the UN Standard Rules for the Equalization of Opportunities for Persons with Disabilities appointed in 1993 recommended the creation of bodies at the governmental level to serve as 'national focal points for disability issues', and accordingly many states parties reported the existence of focal points or costly bodies with responsibilities relating to the development, implementation, and monitoring of policies and programs on disability, and intending to ensure compliance with the Convention. It recommended that States parties to the Convention or states considering ratifying it should evaluate existing institutions to adopt necessary adjustments when needed and in compliance with Article (33). Though the agreement does not make specific recommendations about the form and functioning of these bodies, some considerations must be taken into consideration. The coordinating body or bodies must be appointed at the highest levels of government, such as at the level of a minister or commissioner within a specific ministry .The coordinating agency or bodies must be established and its mandate defined by legal measures, so that the mandate addresses the need for consistent and coordinated government activities in the field of disability, and allocate sufficient human and financial resources to the coordinating agency or bodies. These bodies must be provided with adequate resources to make a positive contribution to implementing the national strategies and plans adopted by the Convention. The agreement encourages the establishment of a coordination mechanism at the government level in addition to other optional coordination bodies. The coordination mechanism may take the form of an inter-ministerial team to coordinate and implement the agreement in various government departments, sectors, or levels. The agreement also referred to the role of non-governmental organizations, especially civil society organizations, persons with disabilities, and their representative organizations, in monitoring the state's implementation of its obligations .However, it should be noted that the role of civil society organizations will be effective only if the State party to the agreement accepts the optional protocol attached to the agreement, which allows, according to the first article that '[t]he state party in this protocol recognizes the competence of the Committee for the Rights of Persons with Disabilities to receive communications from individuals covered. Its jurisdiction and those who claim to be victims of a State party's violation of the provisions of the Convention, and to consider these communications '

\subsection{National Monitoring Mechanisms for States to Implement Their Obligations}

In addition to appointing institutions entrusted with implementation at the governmental level, the agreement requires states to preserve, reinforce, appoint, or establish a framework for promoting and protecting this agreement and monitoring its implementation. Therefore, the agreement adopts two parallel structures at the national level: the first structure at the government level and is charged with implementation, The second structure at the state level is mandated to promote, protect and monitor implementation, and it is obligated to 
include one or more independent mechanisms and to observe the principles relating to the status and work of national institutions for the protection and promotion of human rights. The agreement leaves discretionary power to States parties to establish specific disability mechanisms or entrusting existing bodies with the task of implementation. In any case, the institution that undertakes the monitoring role must observe the principles related to the status of national institutions and their work in order to protect and promote human rights. The elements of the appropriate framework differ according to the national and administrative systems of the States parties as stipulated explicitly in Article (33) of the agreement: 'the performance of tasks related to promotion, protection and monitoring includes activating awareness and conducting public educational campaigns and answering inquiries from the general public and preparing studies and reports and reviewing legislation and policies from In order to comply with and encourage the harmonization of national laws and practices with international standards, the tasks also include reporting to the government, parliament or any other competent body to consult on human rights and rights of people with disabilities either based on Requesting or at the initiative of the commission itself, participating in reports that the state is obligated to submit to the United Nations bodies and committees, and encouraging ratification or accession to human rights instruments and ensuring their implementation, and listening to complaints and appeals'.

States parties must immediately begin, in consultation with national human rights institutions, about the role they can play in monitoring and promoting the Convention as well as involving civil society organizations and persons with disabilities and their representative organizations and engaging them effectively .It is worth noting that the distinction between the UN agreement and other international agreements is that the former has a binding legal force for every country that enforces it. While emphasizing that it is not sufficient to establish these rights, each state must provide appropriate and effective legal systems to guarantee and ensure the fulfillment of these rights, and this is what it is expressed by the international commitment to respect human rights and fundamental freedoms, that is, there is a legal duty that every state bears towards the international community and includes taking all necessary measures to ensure respect and implementation of human rights and fundamental freedoms and refraining from anything that would disrupt this goal and be for the community.

\subsection{International Monitoring of the Implementation of States's Obligations}

As for the international monitoring of the state's fulfillment of its obligations contained in the agreement, it will be through the Committee on the Rights of Persons with Disabilities. The agreement stipulated the formation of an international committee consisting of twelve experts, and the membership of the committee will increase with six members after the agreement gets sixty additional ratifications or accessions to reach its membership limit The maximum amount is of eighteen members, and its members, who work in their capacity, are known for their high morals and recognized for their competence and experience in the field covered by the agreement. The members of the committee are elected by the States parties taking into account the equitable geographical distribution and representation of various trusts: data and principal legal systems, balanced representation of both sexes and the participation of experts with disabilities, the term of office of four viable years and be renewable once, and obtained by holders of experts missions of the United Nations as stipulated in the relevant items in the United Nations Convention on the Privileges and Immunities. The progress of States parties to the Commission reports on the implementation of the Convention through the Secretary-General of the United Nations so that these comprehensive reports of all the measures taken to implement their obligations under this Convention and the extent of achieved progress in this regard, within two years after the entry into force of the Convention for the State Party concerned. After that period, the States parties should submit their reports at least every four years, as well as whenever the committee requests them to do so, and the committee examines each report and presents whatever suggestions and recommendations it deems appropriate. The State party may respond to the committee with any information that it chooses, and the committee may also guide the State party, if requested, with any additional information related to the implementation of this agreement. If the state party delays in submitting the report, the committee may notify the State party of the necessity to examine the application of this agreement thereto .If the state party does not submit the relevant report within three months, the committee is entitled to, as it deems appropriate, to refer to the specialized agencies of the United Nations funds and programs, and other competent bodies, any reports of any reports from the states parties that include a request for advice or technical assistance or indicate their need for such advice or assistance, and to accompany them with the Committee's observations and its recommendations come in connection with these requests or references, if any.

\section{Conclusion}

Following the ratification of the 2007 UN Treaty for persons with disabilities, much effort has been produced by the Jordanian Hashemite Kingdom to enhance and promote the rights of these persons. The main guideline of the treaty was to promote their rights without acknowledging them with special rights. Therefore, this initiative is 
more or less an administrative step, but in the legal practice, few have been achieved. Indeed, the Jordanian Constitution does not include any text relating to their special status. As an example, this particular group has no legal representative in the national institutions. Few texts in penal law relate to their protection, except only one text related to cyber-crimes. Undoubtedly more has to be achieved at the national level to be in adequacy with International legal texts.

\section{Recommendations}

Disabled persons form a category of the population who needs further legal protection, especially by regulation under the principle of equality. It is necessary to amend the Jordanian Constitution by adding texts that acknowledge the special needs of those persons;

Persons with disabilities need the right to justice and the recognition of their identity and dignity must be assured by the law.

The Jordanian Criminal Law does not assure them of the necessary protection. No text may refer to this particular group.

\section{References}

Al-Ma'ita, A. (2008). Fundamental principles to the requalification of disabled persons. Dar Al-Tarek.

Ben Issa, H. (2016). The legal protection of disabled persons. Algeria, 2016.

Daoud, M. (2018). The guarantee of rights of disabled persons in the Iraqi Constitution. Majala al-Qanoun wa al-Siyasa.

Lang, R. (2011). Implementing the United Nations Convention on the rights of persons with disabilities: principles, implications, practice and limitations. Alter, 5(3), 206-220.

Mounib, O. (2008). The new orientation of the protection of disabled persons. Cairo.

Quigley, N, (Ed.). The United Nations Convention on the Rights of Persons with Disabilities: From the Perspective of Young People. Disability Studies Quarterly Winter 2009, Volume 29, No.1.

Shaw, M., (2009). International Law. Cambridge Press.

Zidane, Z. H. (2009). Legal Protection of Disabled Persons in Shari'a Law. Cairo, Dar Al-Koutoub.

Official Documents

The Universal Declaration of Human Rights, 1948.

The Universal Declaration of Rights of Handicapped Persons, 1975.

The Convention on the Rights of Persons with Disabilities, 2007.

The Jordanian Constitution.

The Jordanian Law for the protection of disabled persons.

Jordanian Criminal Law.

The Jordanian Committee for the Rights of disabled persons. http:www.hcd.gov.jo

\section{Copyrights}

Copyright for this article is retained by the author(s), with first publication rights granted to the journal.

This is an open-access article distributed under the terms and conditions of the Creative Commons Attribution license (http://creativecommons.org/licenses/by/4.0/). 